\section{Japan ready for home-grown commercial satellite services}

Tokyo

JAPAN's National Space Development Agency (NASDA) successfully launched a communications satellite last week, opening the way to commercial satellite services in Japan. But the satellite and a twin launched earlier this year will face strong competition from US-made satellites to be launched shortly by private corporations in Japan.

The 0.5-tonne Sakura-3b satellite was launched on Friday from NASDA's Tanegashima space centre by an $\mathrm{H}-1$ rocket. If all goes according to plan, in about 3 months the satellite will be placed in geostationary orbit alongside Sakura3a, launched in February.

Most of the satellites' communication channels will be used by Nippon Telegraph and Telephone (NTT) to establish telecommunications links with remote Japanese islands and alternative nationwide trunk lines. But 13 other government and private organizations will use the satellites for purposes ranging from emergency communications during disasters to in-house video transmissions

\section{Japan's mini-shuttle sinks before lift-off}

\section{Tokyo}

AN attempt by Japan's Institute of Space and Astronautical Sciences (ISAS) to launch a mini-shuttle into the upper atmosphere failed last week when the shuttle sank in the Pacific Ocean with its booster rocket still primed for blast-off.

The 2-m experimental shuttle lifted off from the institute's space centre in Kysuhu cradled in a gondola that dangled beneath a

\section{IMAGE UNAVAILABLE FOR COPYRIGHT REASONS}

\section{Japanese mini-shuttle}

giant balloon. The balloon was supposed to rise to a height of $20 \mathrm{~km}$ at which point the shuttle's booster rocket would have been fired to blast the shuttle to a height of $80 \mathrm{~km}$ for a test re-entry into the Earth's atmosphere. But after reaching a height of only $18 \mathrm{~km}$ the balloon began to descend, and ISAS scientists were forced to separate the balloon from the gondola which parachuted back to Earth. When the gondola splashed down in the Pacific the \$2 million shuttle sank.

David Swinbanks surveillance purposes. between branches of private companies.

The competition will begin to show itself next year. Japan Communications Satellite Co. (JC-Sat), a joint venture of the Japanese trading giants $\mathrm{C}$. Itoh and Mitsui \& Co. with Hughes Communications Inc. of the United States, will launch two giant satellites next year, one with a European Ariane rocket, the other on a US Titan rocket.

Similarly, the Space Communications Corporation established by Mitsubishi Corporation and Mitsubishi Electric plans to launch two satellites next year built by Ford Aerospace of the United States.

The JC-Sat satellites will be more than twice the size of the Sakura twins, with 32 as opposed to 12 transponders each. Furthermore, the US-made transponders will cost only about two-thirds as much as those developed in Japan. And NTT, which is now privatized, has hinted that in future it may not use satellites developed by the Japanese government.

Nevertheless, Japan's Science and Technology Agency, to which NASDA is affiliated, is pushing on with development of the next generation of communications satellites. The agency has asked for over $¥ 6,000$ million ( $\$ 45$ million) to develop the Engineering Test Satellite VI, a giant 2-tonne communications satellite scheduled for launch in 1992. David Swinbanks

\section{Shuttle launch set for today}

\section{Washington}

THE space shuttle Discovery is due to be launched today, 29 September, marking the resumption of the US space programme more than two and a half years after the explosion of Challenger. Safety procedures for the launch have been tightened, and flight controllers will not waive any of the requirements.

Despite some concern last week when it was discovered that the booster which underwent the final ground test had been fitted with an O-ring of old design, Discovery is as mechanically well-prepared as any vehicle that the National Aeronautics and Space Administration (NASA) has launched. The five crew members, led by 47-year-old Frederick Hauck, are all veterans of previous shuttle flights.

Although the time since the Challenger accident has been taken up with a complete overhaul of the shuttle's design, there are still many unanswered questions about the purpose of the shuttle program. The revised safety management procedures mean that shuttle flights will be more expensive and less frequent than was originally planned, and the notion of the shuttle as an economical conveyor of cargo into space has been lost. But NASA's efforts mean that the shuttle will be the main focus of the agency for some time yet.

\title{
Satellite launch marks Israel's calling card to the space age
}

Tel Aviv

ISRAEL launched its first satellite, the Offeq 1, last week, becoming the first Middle Eastern power with the capacity to gather its own intelligence on neighbouring countries from space.

Israeli leaders across the political spectrum immediately praised the launch. Professor Yuval Ne'eman, chairman of the Israeli Space Agency, called it "our calling card to the space age". Offeq lifted off from a beach south of Tel Aviv and is being monitored by the MBT Systems and Space Technology plant, part of Israel Aircraft Industry's (IAI) electronics division.

Officials claim that the 153-kg Offeq is an 'experimental' satellite, and that the current purely civilian project carried only instruments for monitoring the spacecraft's own performance. Ne'eman denied reports that it was carrying a $3-\mathrm{kg}$ payload for

IAI claims the purpose of the launch is to "demonstrate a capability to orbit a satellite and to check the functional ability of its subsystems in a space environment". Many local and foreign observers believe that this test launch paves the way for Israel to send a military satellite into space, reducing reliance on the United States for intelligence information. An added motivation for developing the necessary technology, some sources suggest, was concern that the United States was filtering some information gathered by its own satellites and withholding it from Israel. Ne'eman does not comment on these suggestions. But he does say that the current practice of conducting scientific and technical experiments via the satellites of other countries, predominantly the United States, will continue for some time. But when the next Israeli satellite is ready, it will carry two scientific experiments now being developed. Ne'eman hopes the next launch will be "within a year or two, depending on economics". He said that the success of Israel's satellites will be partly determined by IAI's ability to find customers for its launch services.

Lisa Perlman 